\title{
Considerações sobre o fazer do psicólogo nos processos jurídicos: 0 lugar da subjetividade nas varas da infância e juventude
}

\author{
Angela Bucciano do Rosário \\ Juliana Marcondes Pedrosa de Souza \\ Fuad Kyrillos Neto
}

\section{RESUMO}

O principal objetivo deste estudo é refletir o trabalho do psicólogo, no que concerne à abordagem da subjetividade em processos judiciais envolvendo crianças e adolescentes. A metodologia utilizada foi a análise de conteúdo na leitura integral de três processos jurídicos selecionados pela Promotoria da Infância e Juventude de um município brasileiro de médio porte, devido à morosidade na tramitação de processos envolvendo crianças e adolescentes assistidos em serviços vinculados ao Sistema Único de Assistência Social (SUAS). Os resultados apontam que o lugar da criança e do adolescente nos processos jurídicos é marcado por uma preocupação exacerbada com a garantia de direitos, sem relação com a escuta da singularidade de cada caso, demonstrando a falta de especificidade na prática do psicólogo.

Palavras-chave: infância e juventude; direito; psicanálise; relatório psicológico

\section{ABSTRACT}

Considerations about the duty of a psychologist in the legal processes: The place of subjectivity in the childhood and youth courts.

The main objective of this study is to reflect the psychologist's work, regarding the subjectivity approach in judicial processes involving children and adolescents. The methodology used was the analysis of content in the integral reading of three legal processes selected by the Prosecution of Childhood and Youth of a medium-sized Brazilian city, due to delays in the processing of cases involving children and adolescents assisted in services linked to the Unified System of Social Assistance (SUAS). The results point out that child and adolescent position in legal processes is marked by an exacerbated concern with the guarantee of rights unrelated to listening to the singularity of each case. It demonstrates the lack of specificity in the practice of the psychologist.

Keywords: childhood and youth; Law; psychoanalysis; psychological report

A história social da criança, segundo Áries (1978), foi marcada por diversas formas de violência, como negligência, abandono, maus tratos e abusos em geral. O lugar da criança nos espaços públicos e privados era caracterizado pelos fundamentos da obediência e do silêncio. Incapaz juridicamente, sua palavra não chegava à cena jurídica, porque era filtrada por seus representantes legais e desacreditada pelos operadores do campo do Direito.

Essa história revela também a falta de autonomia da família para educar e assistir seus filhos. Tais fatos são revelados a partir das legislações referentes à infância e à juventude no Brasil. Antes da promulgação do Estatuto da Criança e do Adolescente - ECA -, o Brasil contava com uma legislação em que o domínio da ação jurídica sobre a infância era explícito. (Brasil, 1990)

\author{
Sobre os Autores \\ A.B.R. \\ orcid.org/0000-0002-6831-8715 \\ Pontifícia Universidade Católica \\ de Minas Gerais (PUC-Minas) - \\ Barbacena, MG \\ angelabucciano@gmail.com

\section{J.M.P.S.} \\ orcid.org/0000-0001-7801-0098 \\ Universidade Federal de São \\ João del Rei - São João del-Rei, \\ MG \\ juliana.marcondes@yahoo.com. \\ $\mathrm{br}$ \\ F.K.N. \\ orcid.org/0000-0001-8071-0907 \\ Universidade Federal de São \\ João del Rei - São João del-Rei, \\ MG \\ fuadneto@ufsj.edu.br
}

\section{Direitos Autorais}

Este é um artigo de acesso aberto e pode ser reproduzido livremente, distribuído, transmitido ou modificado, por qualquer pessoa desde que usado sem fins comerciais. 0 trabalho é disponibilizado sob a licença Creative Commons CCBY-NC.

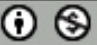




\section{H. INTERACÃO EM LF PSICOLOGIA}

Angela Bucciano do Rosário, Juliana Marcondes Pedrosa de Souza e Fuad Kyrillos Neto
Voltado para uma ideologia da compaixão, o Código de Menores de 1927 tinha como prerrogativa a ideia de carência, ou seja, aquele a quem falta algo, e não a de privação, cujo sentido é o daquele a quem não é possibilitado o acesso. Em 1979 foi instituído o Novo Código de Menores, baseado na doutrina da situação irregular.

Entendia-se por situação irregular crianças e adolescentes pobres, carentes, autores de atos infracionais, sem qualquer distinção entre esses sujeitos. Nessa doutrina, aqueles que se encontram nessa posição "irregular" estão sujeitos à total intervenção do âmbito público. Deste modo, a lei não era para todos, apenas para aqueles que não se enquadrassem em determinadas situações descritas. $\mathrm{Na}$ terminologia adotada pelo código da época, carentes, abandonados, inadaptados e infratores eram tratados da mesma maneira. Assim, as mesmas medidas judiciais eram adotadas nos casos sociais e nos de natureza jurídica. Crianças e adolescentes pobres, abandonados ou infratores eram objetos de vigilância da autoridade pública.

A desqualificação das famílias em situação de pobreza, tratadas como incapazes, deu sustentação ideológica à prática recorrente da suspensão provisória do poder familiar ou da destituição dos pais e de seus deveres em relação aos filhos (Brasil, 2006). Este argumento ideológico possibilitou ao Poder Público o desenvolvimento de políticas paternalistas voltadas para o controle e a contenção social, principalmente para a população mais pobre (Brasil, 2006).

Visando reverter a situação policialesca, que por vezes intervia de forma punitiva nas famílias em situações de vulnerabilidade diversas, em 1990 é promulgado o ECA. Baseado na doutrina da proteção integral, o estatuto considera a criança e o adolescente sujeitos de direitos, independentemente de sua condição social. Nesse sentido, supera o binômio compaixão/repressão e o assistencialismo e passa a considerar a criança e o adolescente como sujeitos de direitos exigíveis com base na lei (Costa, 2004).

As políticas públicas de assistência à criança e ao adolescente são um instrumento necessário para que o Estado possa exercer sua função de promoção da cidadania.

Nesse contexto, em janeiro de 2004 é criado o Ministério do Desenvolvimento Social e Combate à Fome - MDS. 0 MDS, como responsável pelas políticas nacionais de desenvolvimento social, de segurança alimentar e nutricional e da assistência social, implanta a Política Nacional de Assistência Social - PNAS (Brasil, 2005) e o Sistema Único de Assistência Social - (SUAS) (Brasil, 2004). O SUAS reordena a política de assistência social que se organiza de forma descentralizada em seus equipamentos. Tais equipamentos atuam de acordo com o tipo de proteção social e por níveis de complexidade do atendimento.
Assim, um dos equipamentos de referência do SUAS é o Centro de Referência de Assistência Social - CRAS - que, por atuar no nível da proteção social básica, tem a função de contribuir para a inclusão social a partir do fortalecimento dos vínculos familiares, comunitários e sociais, bem como a inserção na rede de serviços.

Outro equipamento é o Centro de Referência Especializado de Assistência Social - CREAS - que intervém no nível da proteção social especial, em serviços especializados direcionados a famílias e indivíduos em situação de ameaça ou violação dos diretos, como: violência física, psicológica, sexual, cumprimento de medida socioeducativa em meio aberto, entre outras (Brasil, 2005).

Entendemos que é necessário que o Estado cumpra sua função promotora da vida social. Nesse sentido, a proteção integral a que tem direito as crianças e adolescentes deve ser viabilizada por intermédio de equipamentos comunitários e da rede de serviços local.

Um importante instrumento para viabilizar a particularidade dos sujeitos atendidos nas políticas públicas de assistência social é o Plano de Atendimento Individual e Familiar, preconizado nas Orientações Técnicas: Serviços de Acolhimento para Crianças e Adolescentes (Brasil, 2009). Esse instrumento envolve a escuta da criança, do adolescente e de sua família e é realizada por técnicos e integrantes da rede de apoio. A ideia é considerar caso a caso, no singular, as possibilidades para o enfrentamento de situações de risco, violação de direitos e responsabilização.

Embora reconheçamos os avanços na perspectiva das políticas públicas da assistência social, a possibilidade de reconhecer um sujeito vai além da legitimação de um indivíduo de direitos. A questão que nos interroga é: como a construção de um fazer que considere o sujeito em sua singularidade pode abarcar, de forma única, o que a política oferece de maneira universal?

Abordaremos essa discussão na perspectiva psicanalítica. Ela nos permite sustentar a profícua discussão acerca da disparidade entre o cidadão e o sujeito, sendo que o primeiro é considerado em sua esfera de direitos e deveres perante a sociedade e que o segundo traz em seu discurso a dimensão da singularidade.

Nesse preâmbulo entendemos que, apesar da legitimidade de sujeitos de direitos, a leitura dos relatórios psicológicos nos indicará que o melhor interesse da criança e do adolescente se faz a partir da visão daqueles que dizem deles entender. Não basta dispor de proteção integral e garantias judiciais se os operadores desse processo não trabalharem com a escuta e a construção do caso que promovam a efetivação singular de seus direitos. Será 


\section{W'INTERACÃO EM ET. PSICOLOGIA}

possível perceber que, mesmo após serem reconhecidos como sujeitos de direitos, continuam sendo falados pelo outro, que tem, por lei, o dever de protegê-los.

Os processos judiciais estudados, que culminaram na apresentação sintética que faremos em seguida, são ilustrativos dos impasses de considerar o singular no universal, proposto na garantia de direitos.

o contexto do trabalho do psicólogo, em interface com o Direito, no que concerne à sua prática junto às Varas da Infância e Juventude, é um campo em construção considerado fundamental no auxílio dos operadores do Direito que trabalham em prol dos interesses da criança e do adolescente.

O psicólogo compõe, assim, as equipes multidisciplinares, recebendo demandas de acompanhamento dos casos nos processos que tramitam nessas varas. No escopo deste manuscrito, interessa-nos refletir, com os relatórios analisados, o trabalho do psicólogo, no que concerne à abordagem da subjetividade dos envolvidos nos processos, a partir de operadores conceituais que balizem a prática deste profissional. Neste manuscrito propomos os seguintes operadores conceituais de extração psicanalítica: escuta, desejo e sujeito, que de modo articulado possibilitam uma práxis clínica em uma instituição.

O Conselho Nacional de Justiça Brasileiro, no provimento $n^{\circ} 36 / 2014$, dispõe sobre a estrutura e os procedimentos das Varas da Infância e Juventude. Nesse provimento considera a importância da ação integrada com os órgãos da gestão das políticas de assistência social, educação e saúde, nos âmbitos municipal e estadual, no trabalho de garantia de direitos de crianças, adolescentes e suas famílias. Essa ação tem por finalidade evitar a demora excessiva na tramitação de processos. Entendemos que os saberes do campo psicológico devem contribuir para a celeridade na tomada de decisões dos magistrados.

\section{MÉTODO}

Trata-se de um termo de cooperação técnica celebrado entre uma universidade pública e a Promotoria de Defesa da Infância e Juventude de uma cidade de 120 mil habitantes no interior de Minas Gerais, tendo como objetivo o estudo e levantamento de dados técnico científicos, propiciando uma análise crítica das ações executadas pelos serviços vinculados ao Sistema Único de Assistência Social (SUAS) do município, especificamente o Centro de Referência de Assistência Social (CRAS) e o Centro de Referência Especializado de Assistência Social (CREAS).

A promotora titular, por intermédio do termo de cooperação técnica assinado entre as instituições, concedeu um termo de autorização, que permitiu o acesso aos autos de procedimento e análise documental coligida, notadamente a cópia dos autos por ela indicados como paradigmáticos para fins de elaboração de pesquisa. Ressalta-se que foi preservado o direito à privacidade das imagens de crianças e adolescentes envolvidos.

Foram selecionados quatro processos pela titular da promotoria, a partir da constatação da demora excessiva na tramitação destes processos, que ela considerava morosos e com elevado número de instituições envolvidas. A lentidão destes processos, segundo a promotoria, privava crianças e adolescentes de uma convivência familiar, culminando no risco de institucionalização destes jovens. Dentre os processos selecionados, a equipe de pesquisa optou pela exclusão de um deles, por não conter relatórios psicológicos na documentação coligida, uma vez que o foco da pesquisa é o fazer do psicólogo nos processos jurídicos na Vara da Infância e Juventude.

A composição dos processos caracterizados como medidas protetivas e solicitação de providências, sofria variações atinentes às suas peculiaridades. Entretanto, de modo geral, cada processo continha relatórios psicológicos do CRAS, relatórios psicológicos do Poder Judiciário, relatórios sociais do CRAS e da Assistência Social Judicial. Além dos relatórios, constavam também pareceres de serviços envolvidos nos casos, tais como de escolas, Unidade Básica de Saúde, Núcleo de Apoio à Saúde da Família (NASF) e do Conselho Tutelar.

A equipe de pesquisa contou com profissionais vinculados ao Departamento de Psicologia da Universidade conveniada, ou seja, psicólogos sem vínculo profissional com a promotoria. As análises foram feitas a partir da leitura integral de cada processo indicado. Todos os integrantes da equipe de pesquisa leram os processos na íntegra, com especial atenção aos relatórios psicológicos, e assinalaram os fatos que se mostravam recorrentes nos documentos. A preocupação dos pesquisadores foi verificar a contribuição do profissional psicólogo no contexto retratado nos processos, com vistas a colaborar para o equacionamento do conflito instalado, visando a agilidade do processo.

A análise de conteúdo constituiu uma metodologia usada para descrever e interpretar o conteúdo desses processos. Essa análise nos conduziu a descrições sistemáticas, o que nos possibilitou reinterpretar as mensagens e atingir uma compreensão de seus significados, para além de uma mera leitura (Bardin, 1977).

Os processos selecionados abrangem as seguintes temáticas: 


\section{H NTERAC̄öEM PSICOLOGIA}

1. Adolescente negligenciada pela mãe encontra-se em situação de risco;

2. Mãe e filhos em situação social precária sofrem agressão por parte do pai;

3. Crianças e adolescente vítimas de negligência e abuso por parte do pai após morte da mãe.

Após a leitura dos materiais, surgiram as seguintes categorias que incidem diretamente sobre os impasses encontrados na assistência à infância e adolescência, quais sejam: nos espaços sociais e o contato com a alteridade, indispensáveis para o surgimento do sujeito em uma proposta clínico-institucional.

\section{RESULTADOS: A MASSIFICAÇÃO DA GARANTIA DOS DIREITOS}

Nos processos analisados foi observada a repetição sistemática de conteúdo nos relatórios psicológicos e nos relatórios sociais. Cumpre-nos ressaltar a diferenciação entre

Quadro 1: Sintese dos conteúdos recorrentes encontrados nos três processos analisados

\begin{tabular}{ll}
\hline \multicolumn{1}{c}{ Categorias } & \multicolumn{1}{c}{ Conteúdos } \\
\hline \multirow{2}{*}{ Encaminhamentos excessivos e sobrepostos } & Encaminhamento para Conselho Tutelar; \\
& Abrigamento solicitado pelo Conselho Tutelar; \\
& Encaminhamento NASF; \\
& Encaminhamento CRAS; \\
& Encaminhamento para Ministério Público. \\
\hline Relatórios Repetitivos e descritivos & - Relatório psicológico do CRAS descreve condições de \\
& moradia e possibilidades de subsistência da família; \\
& - NASF: Relato cronológico e descritivo dos fatos ocorridos \\
& com o falecimento da genitora; \\
& - Relatório social descreve a casa (barraco com chão batido, \\
& fogão a lenha, cozinhando feijão e arroz). \\
\hline Falta de especificidade profissional nos relatórios & - Relatório de visita domiciliar realizada pelo Serviço Social e \\
& comissário da infância. Relata sobre o colchão rasgado, \\
& eletricidade improvisada e afirma que o Sr. M. está com \\
& cheiro de álcool; \\
& - Relatório psicológico afirma que o Sr. M. informou estar \\
& trabalhando, mas foi encontrado em casa, com hálito \\
& alcoólico; \\
& - Relatório psicológico afirma que crianças e adolescentes \\
& estão vivendo sem qualquer regra ou limite.
\end{tabular}

De forma geral, o estudo dos processos nos possibilitou produzir a interpretação de que esses elementos nos dizem da ausência de especificidade do fazer do psicólogo que atua nas diversas instituições envolvidas nos processos estudados. Neste cenário, a clareza, por parte dos psicólogos, em relação aos operadores conceituais de intervenção clínico-institucional, auxiliaria este profissional a considerar os casos em sua singularidade, contribuindo com alguma resolutividade para os impasses subjetivos presentes no contexto processual.

Esses operadores conceituais nos sinalizam, em uma perspectiva universal, o que é o fazer do psicólogo, que, embora sustentado a partir do caso a caso, se encontra fundamentado na legislação. O ECA, ao considerar a criança e o adolescente sujeitos de direitos, possibilita sua inserção estes documentos normatizados pelos conselhos profissionais.

Segundo resolução do Conselho Federal de Psicologia (CFP) o relatório psicológico é uma apresentação descritiva acerca de situações e/ou condições psicológicas e suas determinações históricas, sociais, políticas e culturais, pesquisadas no processo de avaliação psicológica. Este documento deve ser subsidiado em dados colhidos e analisados à luz de um instrumental técnico. Nesse instrumental estão incluídas as intervenções verbais e o exame psíquico. O CFP orienta que este documento deve ser consubstanciado em um referencial técnico-filosófico e científico adotado pelo psicólogo.

Quanto à finalidade, o relatório psicológico deve, ainda 


\section{W'INTERACÃO EM PSICOLOGIA}

segundo o CFP, apresentar os procedimentos e conclusões gerados pelo processo da avaliação psicológica, relatando o encaminhamento, as intervenções, o diagnóstico, o prognóstico e a evolução do caso, orientação e sugestão de projeto terapêutico, limitando-se a fornecer somente as informações necessárias relacionadas à demanda, solicitação ou petição (Conselho Federal de Psicologia, 2003).

O estudo de caso social, segundo o Conselho Federal de Serviço Social (CFESS) é, historicamente, a maior demanda de atribuição ao/à assistente social no sociojurídico. Existem diversas perspectivas acerca do estudo de caso social encontradas na literatura. No escopo desse artigo e, em consonância com o entendimento do CFESS, podemos afirmar que é um documento no qual o assistente social apresenta uma determinada situação social, em vista da garantia de direitos dos sujeitos envolvidos (Conselho Federal de Serviço Social, 2014).

Interessa-nos os relatórios confeccionados por profissionais psicólogos, uma vez que tal estudo indica a ausência de especificidade técnica e interventiva desse profissional. Exemplos dessa problemática encontram-se nos relatórios psicológicos analisados.

Em um primeiro processo, observamos que o relatório psicológico repete os mesmos argumentos do estudo de caso social que foram apresentados com um tom investigativo-policial. 0 conteúdo do documento informa endereço, telefone de parentes da adolescente, sugerindo condutas baseadas no senso comum, como por exemplo: "sugiro que a adolescente permaneça com a [parente] que parece ser pessoa idônea e tem pulso firme". As conclusões desse relatório psicológico não apontam para a especificidade profissional e o documento apresenta afirmações pontuais baseadas em observações ordinárias de fatos cotidianos.

Ainda nesse aspecto, outro processo, referente ao pedido de providência acerca de um marido que agride a mulher e filhos, apresenta um relatório psicológico do Centro de Referência da Assistência Social (CRAS), que prioriza a descrição da visita domiciliar realizada. Neste relato constam as condições da moradia, o estado de ânimo da família e as soluções encontradas para subsistência. Também em tom investigativo apresenta a rotina da família "Sr M. que informou estar trabalhando, foi encontrado em casa às 15 horas e já tinha ingerido álcool".

No mesmo processo, em outro relatório realizado pela psicóloga judicial, encontramos relatos de entrevista com membros da família, na tentativa de auxiliar o juiz a decidir sobre a pensão alimentícia e visita dos filhos. As considerações do documento apontam soluções pragmáticas de garantia de direitos, mas não apresentam indicações do instrumental teórico pertinente ao campo Psi, ou seja, a especificidade da área que possa contribuir para o auxílio do juiz na construção de intervenções que possam efetivar esses direitos.

Por fim, um terceiro processo de solicitação de medida protetiva se instaura com a justificativa de violência doméstica sofrida por duas crianças e uma adolescente, tendo o pai como suspeito. Diante do falecimento da genitora, o NASF e CRAS solicitam abrigamento imediato das crianças, mediante o fato de a mãe ter relatado, no acompanhamento dessas instituições, a situação de violência. Diante do abrigamento, a justiça solicita relatório do CRAS com vistas a se inteirar da dinâmica familiar. Porém, o relatório psicológico apresenta uma descrição cronológica dos fatos ocorridos. Nesse relatório não consta qualquer alusão ao fato levantado pelo NASF. O relatório não apresenta a manifestação da adolescente acerca da questão que mobiliza o serviço, fato este que coloca em questão a efetividade das medidas adotadas.

No mesmo processo, em um segundo relatório elaborado pelo NASF, temos a suspeita de violência justificada pela fala da genitora quando era atendida no serviço, sem que haja uma escuta das crianças e do adolescente. A conclusão do relatório apresenta que o "genitor não tem condições sociais e psicológicas de cuidar das filhas", sem sustentação para tal afirmação.

Por fim, o relatório do CRAS conclui que as "crianças e adolescentes estão vivendo sem qualquer regra ou limite, saindo e retornando para casa a hora que desejam e indo onde querem, estando expostas a diversas violências". O relatório mais uma vez desconsidera a violência sofrida dentro de casa em detrimento da possibilidade de estarem as crianças sendo negligenciadas, já que não estão sob os cuidados da mãe que falecera. Nota-se uma ausência de posicionamento do profissional de psicologia, em relação à situação apresentada pelo Poder Judiciário e Ministério Público, que solicita estudo social da família e inclusão em atendimento psicossocial das crianças, diante da suspeita de violência sexual.

Diante da observação desses documentos, podemos nos questionar sobre o lugar da criança nos processos jurídicos. Sendo alvo direto dessas intervenções que se prestam a garantir seus direitos, vemos surgir uma preocupação exacerbada quanto à sua proteção, que está descolada de uma possibilidade de escuta, já que se pratica o engodo de atribuir o que é o bem comum sem pensar na singularidade de cada caso. 


\section{DISCUSSÃO: O (NÃO) LUGAR DAS CRIANÇAS NOS PROCESSOS JURIDICOS}

Asseveramos que a especificidade do saber da Psicologia e a agilidade no encaminhamento das demandas devem vir acompanhadas de uma escuta do singular. Para tanto, um importante instrumento para viabilizar a particularidade dos sujeitos que estão envolvidos nesses processos seria a escuta que resgata a singularidade dos casos, apontando construção de saídas diferenciadas para o enfrentamento de situações de risco e violação de direitos.

Lembramos que Garcia (1997), ao propor uma clínica do social, indica que tal modalidade deve enodar o interesse e a atenção que a clínica requer à subjetividade, articulando tais procedimentos com um programa de ação política como prática no cotidiano do cidadão. Para atingir esse fim, afirmamos a necessidade de contar com profissionais com interesse na experiência clínica e na escuta do sujeito, além de considerar a importância das questões políticoinstitucionais que envolvem o campo de atenção da criança, do adolescente e de suas famílias.

o psicólogo, mesmo tendo como objetivo em suas intervenções a garantia de direitos dessas crianças e adolescentes, ao trabalhar com a escuta, possibilita o resgate da dimensão subjetiva nos processos jurídicos que thes dizem respeito. (Souza \& Moreira, 2014).

Para tanto, se faz imperativo operarmos com o conceito de sujeito em comparação ao cidadão. Podemos afirmar que como ser de linguagem, o sujeito humano se constitui no domínio do verbal. Trata-se de um domínio de um campo que contém e subsume o sujeito. (Souza \& Moreira, 2014):

Lacan, no seminário 11 , no capítulo intitulado Do sujeito da certeza diz:

[...] Freud, onde duvida... está seguro de que um pensamento está lá, pensamento que é inconsciente, o que quer dizer que se revela como ausente. É a este lugar que ele chama, uma vez que lida com outros, o eu penso pelo qual vai revelar-se o sujeito. Em suma, Freud está seguro de que esse pensamento está lá, completamente sozinho de todo seu eu sou, se assim, podemos dizer, - a menos que, este é o salto, alguém pense em seu lugar (Lacan,1964/1998a, p. 39).

Temos, assim, uma dissimetria entre o pensar psicanalítico e o cartesiano. Dissimetria referente à certeza. Em psicanálise, a certeza não é encontrada no analisando, sujeito do pensamento. A certeza se situa no Outro, isto é, no analista.

Elia (2004) aponta que a categoria de sujeito se impõe ao trabalho teórico do analista. 0 conceito de sujeito está implicado em alto grau e na articulação teórica do que Lacan denominou de Os quatro conceitos fundamentais da psicanálise (inconsciente, pulsão, repetição e transferência).

o discurso psicanalítico opera na situação analítica com uma práxis colocada em operação por intermédio do dispositivo freudiano da livre associação. Esse dispositivo permite a emergência do sujeito do inconsciente, por intermédio da repetição e da transferência, e cria as condições de produção das formações do inconsciente (atos falhos, lapsos, sintomas, chistes). Assim, o sujeito é um conceito que se impõe à experiência analítica na exigência de elaboração teórica que faz ao analista.

Tais considerações nos auxiliam na compreensão de que o termo "sujeito" nos possibilita trabalhar com a hipótese do inconsciente, sem aniquilar sua dimensão fundamental de não-sabido. Lacan (1960/1998b) formula a seguinte pergunta: "Qual seja, a maneira certa de responder à pergunta 'Quem está falando?', quando se trata do sujeito do inconsciente?" (p. 815).

A esse respeito, vale lembrar o esclarecimento de Porge (1996), de que esse outro é o sujeito do inconsciente, em sua excentricidade de si para si mesmo. Ele pulsa, se constituindo numa fenda por onde algo de não-sabido se abre e se fecha assim que é apreendido pela consciência. Para o autor supracitado, o sujeito não tem substância, ele surge num momento de eclipse e se manifesta num equívoco.

Com Soler (1997) podemos afirmar que seria profícuo para os sujeitos encontrarem uma escuta que os possibilite transformar o sujeito do sofrimento em sujeito do pensamento, por intermédio da livre associação. Essa técnica transforma o sujeito em produtor de pensamentos. Eis uma diferenciação essencial no trabalho de intervenção institucional: o cidadão situa-se na esfera dos direitos e deveres atinentes à vida comunitária, e o sujeito resulta de um acontecimento pelo qual ele se vê tomado, se faz fiel e, por intermédio do simbólico, tem possibilidade de produzir um saber.

Temos, assim, uma tensão entre o sujeito e o cidadão. É com essa tensão que os psicólogos lidam em seu cotidiano. Almejar a inserção social de crianças e adolescentes em risco pode nos levar a um ideal de adequação social ou salvação. Pensar na inserção do simbólico nos leva a uma prática do bem-dizer, da produção de saber sobre seu sofrimento, que pode ter como consequência a inserção no social a partir de certa peculiaridade.

Acreditamos que o acompanhamento clínico-institucional dos casos minimizaria a institucionalização como via de resposta unívoca para os impasses na assistência. Com Kupfer (2000), asseveramos que a circulação das crianças e adolescentes em distintos espaços sociais, sustentada por 


\section{W'INTERACÃO EM PSICOLOGIA}

uma escuta, possibilita, pela ausência ou hiato que surge entre esses espaços, o surgimento de um sujeito. É sabido que as instituições reproduzem uma cadeia de significantes. Espera-se, pois, que o sujeito surja no intervalo entre eles, seja a criança, o adolescente ou o familiar envolvido no contexto do caso. A proposta com vistas a uma escuta do sujeito, escuta que considera a distância cultural e as diferentes manifestações de sofrimento, favoreceria a introdução da criança/adolescente no registro do simbólico, possibilitando que a intervenção jurídica se implemente a partir da singularidade do caso.

Constatamos, em consonância com Souza e Moreira (2014), que não basta um trabalho orientado apenas pela premissa da criança e do adolescente enquanto sujeitos de direitos, mas faz-se necessário que a escuta do sujeito de direito se faça enodada com a escuta do sujeito do desejo. É possível pleitear a garantia de direitos por intermédio da escuta da singularidade.

Com base na afirmação das autoras supracitadas, asseveramos que as intervenções que deveriam ser construídas caso a caso, conforme acima exemplificadas, são direcionadas em prol do saber universal de quem protege e podem produzir um efeito indesejado, como por exemplo, a cronificação institucional de crianças e adolescentes, em detrimento de uma busca de autonomia. Somente a partir do trabalho de escuta é possível ao psicólogo informar aos órgãos competentes as intervenções que garantam direitos, mas também, do ponto de vista psíquico, preservem o melhor interesse da criança e do adolescente.

Trabalhar orientado pela escuta de cada sujeito e seguir as estratégias construídas por cada um implica sustentar a diferença a partir da singularidade que o constitui e não introduzir uma nova ordem que oriente uma prática de regulação subjetiva. Trata-se de fazer da execução das medidas protetivas e socioeducativas um pacto coletivo em torno da possibilidade de cada cidadão advir em sua singularidade. Com isso, ali onde o sujeito está apagado, como é o caso dos processos judiciais, que a resposta dos psicólogos nos pareceres psicológicos se baseie na escuta antes de qualquer coisa, pois só assim poderemos possibilitar a emergência do sujeito, barrando sua submissão a um saber imposto a ele por uma autoridade.

Sabemos, com a psicanálise, que a ideia de sujeito supera a arrogância do eu como totalidade consciente. A subversão proposta por Freud, ao conceber o sujeito não mais como autoconsciente, mas como dividido entre consciente e inconsciente, aponta para tal perspectiva. É na parte inconsciente que estão os desejos que, por sua vez, se manifestam à revelia da parte consciente (Freud, 1900/1996). Nesse sentido, sujeito não é, necessariamente, aquele que sabe o que está fazendo, mas necessariamente é aquele que responde por aquilo que faz.

Nessa perspectiva, todo e qualquer sujeito deve ser considerado no singular, ou seja, a partir daquilo que é impossível generalizar, o desejo. Assim, uma escuta do singular é imprescindível para qualquer atuação junto ao sujeito, seja ele criança, adolescente ou os membros de sua família.

\section{CONSIDERAÇÕES FINAIS}

Partindo de tais considerações, fazemos a aposta de que é possível operar a escuta do singular no âmbito jurídico, considerando os protocolos e as diretrizes generalizantes e universais.

Como vimos acima, são muitos os textos, desde diretrizes e normativas, que indicam a necessidade de constante reavaliação das ações em programas e serviços. Porém, a possibilidade de construir um lugar de escuta, do ponto de vista psicanalítico, deve considerar aquilo que é de mais particular, o reconhecimento do sujeito de desejo. (Brasil, 1990; 2004; 2005; 2006; 2009)

Nesse ponto é importante frisar que o desejo do sujeito o divide e o torna singular, não tendo como pensarmos um sujeito humano com direitos e deveres enunciados universalmente. Lacan (1960/1991) denuncia todas essas tentativas como normalizadoras e adaptativas em sua pretensão de abafar o desejo. Dessa forma, ele afirma, o sujeito deve responder por esse desejo que ele não domina e que, no entanto, traça o seu destino, pois é ali que reside a sua verdade e ele pagará um preço por dizê-la. Nesse sentido, é com o desejo que o sujeito está comprometido e é pela sua enunciação que ele deve tornar-se responsável.

Enfatizamos que na perspectiva psicanalítica a responsabilidade é pela enunciação do desejo. Nesse ponto, é importante lembrar, mesmo de forma breve e esquemática, a diferença entre demanda e desejo. Enquanto a primeira é característica do sujeito falante, pois toda fala é dirigida ao Outro, um objeto sem essência, o desejo incide sobre uma fantasia, ou seja, sobre um outro imaginário. 0 desejo pulsa no intervalo da demanda com o apelo de receber seu complemento do Outro, como lugar da falta (David-Menard, 1996).

Desta forma, concordamos com Scarparo (2008) quando diz que, para além da necessidade, a escuta psicanalítica deve considerar aquilo que na constituição subjetiva faz obstáculo à formulação do desejo. Em outros termos, possibilitar a constituição de uma demanda em que a necessidade impera e, por vezes, impede um desligamento 
necessário para ser possível o reconhecimento da circulação do desejo. Assim, é importante considerar que uma escuta psicanalítica pode permitir a reflexão sobre os efeitos subjetivos que podem suceder com as necessidades mais elementares, mas não confundir seus efeitos com aquilo que é próprio do sujeito. Isso porque, por vezes, a necessidade pode ser um obstáculo no processo de reconhecimento do desejo, e a aderência no objeto da necessidade pode representar um apagamento do desejo. Nesse sentido, a escuta deve considerar a distância cultural e as diferentes manifestações de sofrimento.

A escuta de crianças, adolescentes e suas famílias pode ser obstruída devido à complexidade da situação social. Junqueira (1997) afirma que a psicanálise vive essas vicissitudes e tenta desconstruí-las, buscando atravessar essa assimetria. Nesse sentido, visa alcançar que o analista seja dispensado deste lugar de suposto saber de que foi investido, permitindo ao sujeito passar da submissão de agente da passiva a sujeito desejante, responsável por seus atos e livre em suas escolhas. Assim, afirma a psicanalista, isto se processa num interjogo com a realidade social e política, com todas as singularidades históricas que vão constituir os sujeitos e a sociedade.

Finalizamos com a resposta de Pellegrino à carta de Maria Rita Kehl (1997), na qual afirma que a psicanálise, antes de ser uma profissão, é um empenho existencial, algo que transcende molduras e modelos burocráticos. 0 psicanalista é o contrário do burocrata ou do especialista. Ele escuta o desejo, debruçado sobre o coração selvagem da vida.

\section{CONTRIBUIÇÃO DE CADA AUTOR}

A.B.R. participou da análise dos dados, redação da versão inicial do artigo é da revisão da versão reapresentada; J.M.P.S. participou da análise dos dados e da redação inicial do artigo; F.K.N. participou da análise dos dados, da redação inicial do artigo e da revisão da versão reapresentada.

\section{DECLARAÇÃO DE CONFLITOS DE INTERESSE}

Os autores (as) declaram não possuir nenhum conflito de interesse, atual ou potencial de ordem financeira, pessoal ou institucional no presente artigo.

\section{DECLARAÇÃO DE FINANCIAMENTO}

Financiamento da Coordenação de Aperfeiçoamento de Pessoal de Nível Superior, a partir de bolsa do Programa Nacional de Pós-Doutorado (PNPD/CAPES).

\section{REFERÊNCIAS}

Áries, P. (1978). História social da infância e da família. Rio de Janeiro: LCT.

Bardin, L. (1977). Análise de conteúdo. Lisboa: edições 70.

Brasil. (1990). Lei 8.069 de 13 jul. Dispõe sobre o Estatuto da Criança e do Adolescente e dá outras providências. Diário Oficial da União, Brasília.

Brasil. (2004). Ministério do Desenvolvimento Social e Combate à Fome. Secretaria Nacional de Assistência Social. Política Nacional de Assistência Social PNAS/ Brasília, novembro 2005, reimpresso em maio de 2009.

Brasil. (2005). Ministério do Desenvolvimento Social e Combate à Fome (MDS). Sistema Único da Assistência Social (SUAS).

Brasil. (2006). Secretaria Especial dos Direitos Humanos. Ministério do Desenvolvimento Social e Combate à Fome. Plano Nacional de Promoção, Proteção e Defesa do Direito de Crianças e Adolescentes à Convivência Familiar e Comunitária . Brasília.

Brasil. (2009). Secretaria Especial dos Direitos Humanos. Ministério da Justiça e Cidadania. Orientações técnicas: Serviços de acolhimento para crianças e adolescentes. Brasília.

Conselho Federal de Psicologia. (2003). Resolução CFP no. 007/2003. Institui o Manual de Elaboração de Documentos Escritos produzidos pelo psicólogo, decorrentes de avaliação psicológica e revoga a Resolução CFP N. ${ }^{\circ}$ 017/2002.

Conselho Federal de Serviço Social. (2014). Atuação de assistentes sociais no Sociojurídico: Subsídios para reflexão. Brasília: CFESS.

Conselho Nacional de Justiça. (2014). Provimento no. 36. Dispõe sobre a estrutura e procedimentos das varas da Infância e Juventude.

Costa, A. C. G. (2004). Por uma política nacional de execução das medidas sócio-educativas - conceitos e princípios norteadores. Em: Brasil. Presidência da República. Secretaria Especial de Direitos Humanos. Subsecretaria dos Direitos da Criança e do Adolescente. Belo Horizonte.

David-Menard, M. (1996). Desejo. In Kaufmann, P. Dicionário Enciclopédico de Psicanálise. O legado de Freud e Lacan. Rio de Janeiro: Jorge Zahar Editor. pp. 114-120

Elia, L. (2004). O conceito de sujeito. Rio de Janeiro: Jorge Zahar Editor.

Freud, S. (1996). A interpretação dos sonhos. Em J. Salomão. Edição standard brasileira das obras psicológicas completas de Sigmund Freud (Vol. 4, pp. 157-167). Rio de Janeiro: Imago. (Trabalho original publicado em 1900). 
Garcia, C. (1997a). Clínica do Social (Dissertação de Mestrado). Universidade Federal de Minas Gerais (UFMG), Belo Horizonte, Minas Gerais, Brasil

Junqueira, M. H. R. (1997). Psicanálise de brasileiro. Em: L.A.V. Santos. Psicanálise de Brasileiro (pp. 68-70). Rio de Janeiro: Taurus.

Kehl, M. R. (1997). Leandro, um brasileiro. Em: L.A.V. Santos. (Org). Psicanálise de Brasileiro. Rio de Janeiro: Taurus, p. 40-44.

Kupfer, M.C.M. (2000). Psicanálise e instituições. Correio da APPOA, Porto Alegre.

Lacan, J. (1991). O seminário livro 7. A ética da psicanálise. Rio de Janeiro: Jorge Zahar Editor, (Trabalho original publicado em 1960).

Lacan, J. (1998a). O seminário livro 11. Os quatro conceitos fundamentais da psicanálise. Rio de Janeiro: Jorge Zahar Editor. (Trabalho original publicado em 1964).

Lacan, J. (1998b) Subversão do sujeito e dialética do desejo. Em: J. Lacan. Escritos Rio de Janeiro: Jorge Zahar Editor, (Trabalho original publicado em 1960). p.807-842.
Porge, E. (1996). Sujeito. Em: P. Kaufmann. Dicionário Enciclopédico de Psicanálise. O legado de Freud e Lacan. Rio de Janeiro: Jorge Zahar Editor. p. 501-510

Scarparo, M.L.D.E. (2008). Em busca do sujeito perdido: a psicanálise na assistência social, limites e possibilidades. (Dissertação de Mestrado). Universidade Federal do Rio Grande do Sul, Porto Alegre, Rio Grande do Sul, Brasil

Soler, C. (1997). O sujeito e o Outro I. Em R. Feldstein; B. Fink; M Jaanus. Para ler o seminário 11 de Lacan (pp. 52-57). Rio de Janeiro: Jorge Zahar Editores.

Souza, J.M.P, \& Moreira, J.O (2014) Psicanálise e Direito: Escutar o sujeito no âmbito das medidas socioeducativas. Estudos e Pesquisas em Psicologia, 14(1), 182-200.

Recebido em: 07/11/2016 Primeira decisão editorial em: 25/07/2017 Aceito em: 04/09/2017 